황반원공과 안축장과의 관계: 환자-대조군 연구

\title{
The Relationship between Macular Hole and Axial Length: A Retrospective Case-control Study
}

\author{
조용운 ${ }^{1}$, 이동우 ${ }^{1}$, 최영제 ${ }^{1}$, 최유진 $^{1}$, 유웅선 ${ }^{1,2}$, 정인영 ${ }^{1,2}$ \\ Yong Wun Cho ${ }^{1}$, Dong Woo Lee ${ }^{1}$, Young Je Choi ${ }^{1}$, Yu-JinChoi ${ }^{1}$, Woong-Sun Yoo ${ }^{1,2}$, In Young Chung ${ }^{1,2}$ \\ 1경상국립대학교 의과대학 경상국립대학교병원 안과학교실, ${ }^{2}$ 경상국립대학교 건강과학연구원 \\ ${ }^{1}$ Department of Ophthalmology, Gyeongsang National University Hospital, Gyeongsang National University College of Medicine, Jinju, Korea \\ ${ }^{2}$ Health Science Institute, Gyeongsang National University, Jinju, Korea
}

Purpose: To compare the axial length between patients with macular hole and a control group.

Methods: The axial length was compared and analyzed for 100 eyes of 100 patients diagnosed with idiopathic full thickness macular hole, fellow eyes of patients, and 100 eyes of 100 age-matched control subjects who underwent cataract surgery.

Results: The average axial length was $22.71 \pm 0.92 \mathrm{~mm}$ in eyes of patients with macular hole and was $22.81 \pm 0.89 \mathrm{~mm}$ in fellow eyes of patients. There was no significant difference between axial length of eyes with macular hole and fellow eyes of patients $(p=0.477)$. The average axial length was $23.37 \pm 0.68 \mathrm{~mm}$ in the control group. There were statistically significant differences between the axial length of eyes with macular hole and fellow eyes of patients compared to that in the control group $(p<0.001)$.

Conclusions: Patients with idiopathic macular hole showed significantly shorter axial length compared to the control group, and this might be considered a triggering factor of macular hole.

Keywords: Axial length; Macular hole; Risk factor

서론

특발성 황반원공의 발생 기전에 대해서는 많은 가설들이 발표 되었지만 아직까지 명확하게 규명되지 않았다. 최근까지 중심 와주위 후유리체피질의 수축에 의한 유리체의 전후 방향의 접 선 견인력이 특발성 황반원공의 중요한 발생기전으로 설명되 고 있다[1-5].

황반원공의 유발 요인으로는 연령, 성별, 근시 등 다양한 가 설들이 존재하지만 아직까지 명확한 결론은 없는 상태이다[1,6].
이전의 몇몇 연구에서 안축장이 황반원공의 유발 요인으로 발 표되었지만, 다양한 상반된 의견들이 제시되었으며, 짧은 안축 장 또는 긴 안축장이 황반원공을 일으키는 기전에 대해서 여 러 가지 가설이 있지만 아직까지 확립된 이론 및 결과는 없었 다[7-10].

저자들은 수년간 황반원공 수술을 진행하면서 수술 환자군 에서 짧은 안축장을 가진 경향이 있는 것을 인지하고 안축장과 황반원공 발생과의 관계에 관해 알아보고자 환자 대조군 연구 를 시행하였으며 이전 연구들과 비교하고자 하였다.

\section{Address reprint requests to In Young Chung, MD, PhD}

Department of Ophthalmology, Gyeongsang National University Hospital, Gyeongsang National University College of Medicine, \#79 Gangnam-ro, Jinju 52727, Korea

Tel: 82-55-750-8171, Fax: 82-55-758-4158

E-mail: inyoung@gnu.ac.kr
Received: 2021. 9. 3.

Revised: 2021. 9. 30.

Accepted: 2021. 10. 11. 


\section{대상과 방법}

2015년 1월에서 2020년 12월까지 본원에서 황반원공으로 진단 받은 환자를 대상으로 의무기록을 후향적으로 분석하였다. 본 연구는 본원의 임상연구윤리위원회의 승인하에 진행되었다(승 인 번호: 2021-01-017). 특발성 황반원공 Gass [1] 분류에 따라 빛간섭단층촬영 결과를 확인하고, 한쪽 눈에 황반원공 2 기, 3 기, 4 기 중, 전층황반원공으로 진단받은 환자를 대상으로 하였 다. 외상, 수술 후 발생한 황반원공, 뒤포도종을 동반한 고도근 시 등의 이차성 황반원공은 제외하였고 황반원공 외 안과적 기 왕력과 수술력이 있는 경우는 연구에서 제외하였다. 또한 황반 원공이 없는 건강한 눈에서도 측정값을 수집하였다.

대조군의 경우 동일 기간 본원에서 시행한 단순 백내장 환 자를 대상으로 하였다. 황반원공의 환자에서처럼 외상, 포도 막염, 뒤포도종을 동반한 고도근시 등 이차성 백내장은 연구 에서 제외하였고, 단순 백내장 외 안과적 기왕력과 수술력이 있는 경우 대조군에서 제외하였다. 연구 기간 내의 백내장 수 술 전 검사 자료를 이용하여 황반원공군과 나이, 성별을 일치 시켜 무작위로 선택하였고 다양한 대조군을 위해 환자 한 명 당 수술을 계획했던 단안 자료만 포함시켜 100 명 100 안의 정보 를 수집하였다.

황반원공이 있는 군, 황반원공 환자에서 원공이 없는 반대 쪽 건강한 눈, 대조군으로 나누어 나이, 성별을 수집하고 IOL master $^{\circledR}$ (Carl Zeiss, Inc., Jena, Germany)를 이용하여 안구 길 이를 측정하였다. 또한 굴절력과 전방 깊이를 의무기록을 통해 수집하여 분석하였다. 굴절력은 spherical equivalent로 계산하 였다. 통계적 검정은 Independent-sample $t$-test를 이용하였다. 모든 통계 분석은 SPSS (version 21.0, software for windows;
SPSS Inc., Chicago, IL, USA)를 이용하였으며, $p$ 값이 0.05 미 만인 경우에 통계적으로 유의하다고 판단하였다.

\section{결과}

황반원공 환자는 남자가 15 명 여자 85 명이었으며 평균 나이는 61세였다. 대조군도 연령 성비를 같게 자료를 모집하여 남자 15명 여자 85명이었으며, 평균 나이는 62세로 두 군에서 유의한 차이 는 없었다(Table 1).

황반원공군에서 병변이 있는 눈의 안축장의 평균 길이는 $22.71 \pm 0.92 \mathrm{~mm}$ 였으며, 건강한 눈의 안축장의 평균 길이는 $22.81 \pm 0.89 \mathrm{~mm}$ 였고, 병변이 있는 눈이 건강한 눈에 비해 짧 게 측정되었지만 유의한 차이는 없었다. 대조군의 안축장의 평 균 길이는 $23.37 \pm 0.68 \mathrm{~mm}$ 로 측정되었다. 황반원공눈의 안축 장 길이는 대조군에 비하여 통계적으로 유의하게 짧았으며, 황 반원공군에서 건강한 눈과 대조군을 비교하였을 때 또한 유의 한 차이를 보였다 $(p<0.001)$ (Table 2).

전방 깊이의 경우 황반원공군에서 병변측의 평균은 $2.62 \pm$ $0.21 \mathrm{~mm}$ 로 측정되었으며 건강한 눈의 평균은 $2.63 \pm 0.21 \mathrm{~mm}$, 대조군에서의 전방 깊이 평균은 $2.67 \pm 0.19 \mathrm{~mm}$ 로, 병변측과 건강한 눈, 병변측과 대조군, 건강한 눈과 대조군에서 비교한 결과 유의한 차이는 없었다. 평균 굴절력의 경우 황반원공군의 병변이 있는 눈에서 평균 $0.86 \pm 1.10$ diopters $(\mathrm{D})$ 로 측정되었 고 건강한 눈에서는 평균 $0.82 \pm 1.11 \mathrm{D}$ 로 확인되었다. 대조군 의 경우 $0.56 \pm 1.25 \mathrm{D}$ 로 측정되었고 각 군의 비교에서 유의한 차이는 확인되지 않았다(Table 2).

Table 1. Baseline characteristics of patients

\begin{tabular}{lccc}
\hline & Macular holes $(\mathrm{n}=100)$ & Control $(\mathrm{n}=100)$ & $p$-value \\
\hline Age (years) & $61.3 \pm 3.76$ & $62.1 \pm 1.32$ & 0.799 \\
Sex & & & \\
Male & 15 & 15 & 85 \\
Female & 85 & 85 & \\
\hline
\end{tabular}

Table 2. Axial length of eyes with macular hole, fellow eyes of patients, and the control group

\begin{tabular}{lcccccc}
\hline & Macular holes & Fellow eyes & Control & $p$-value & $p$-value $^{\dagger}$ & $p$-value \\
\hline AXL $(\mathrm{mm})$ & $22.71 \pm 0.92$ & $22.81 \pm 0.89$ & $23.37 \pm 0.68$ & 0.477 & $<0.001$ & $<0.001$ \\
ACD $(\mathrm{mm})$ & $2.62 \pm 0.21$ & $2.63 \pm 0.21$ & $2.67 \pm 0.19$ & 0.749 & 0.079 & 0.162 \\
SE (D) & $0.86 \pm 1.10$ & $0.82 \pm 1.11$ & $0.56 \pm 1.25$ & 0.785 & 0.069 & 0.119 \\
\hline
\end{tabular}

$\mathrm{AXL}=$ axial length; $\mathrm{ACD}=$ anterior chamber depth; $\mathrm{SE}=$ spherical equivalent; $\mathrm{D}=$ diopters.

${ }^{*}$ Compared macular holes and fellow eyes; ${ }^{\dagger}$ Compared macular holes and control; ${ }^{\ddagger}$ Compared fellow eyes and control. 


\section{고찰}

황반원공은 Gass [1]가 1995년 황반원공에 대한 분류와 원인으 로 접선견인력을 발표한 이래로 원인 및 유발 요인에 대한 다양 한 의견들이 발표되었다. 원인에 대해서는 유리체의 전후견인력 이 대표적인 가설로 알려지고 있으며[1-5], 유발 요인에 대하여 는 굴절력, 나이, 성별, 안축장 등이 발표된 적이 있으나 아직까 지도 의견이 다양하고 명확한 견해는 알려져 있지 않다. 따라서 다양한 후속 연구 및 자료가 필요할 것으로 생각되며 본 연구 도 특발성 황반원공의 유발 요인을 유추해 볼 수 있는 연구 중 의 하나로서 도움을 줄 수 있다.

이번 저자들의 연구에서는 황반원공 환자에서 안축장이 대조 군에 비하여 더 짧게 나타나는 것을 확인할 수 있었다. 연구 대 상은 한쪽 눈에 발생한 특발성 황반원공으로 한정하여 병변이 발생한 눈과 건강한 눈과의 차이를 비교해 보았고, 이차성 황반 원공은 특발성 황반원공과는 다른 기전으로 황반원공이 발생 할 수 있어 분석에서 제외하였다. 또한 대조군을 선정하는 과정 에서 단순백내장 환자만을 이용하여 황반원공군과 같은 기준 으로 자료를 수집하였다. 외국 연구에 의하면 나이대별 정상 안 축장 길이는 60 세에서 69 세 사이의 경우 $23.40 \mathrm{~mm}$ 로 발표된 적 이 있으며, 이는 저자들의 대조군의 안축장 길이와 비슷한 결과 이다[11]. 또한 앞서 발표된 황반원공과 안축장과의 관계에 대한 연구에서 측정된 대조군의 안축장들과도 유사하여 대조군 표 본으로 적절한 것으로 생각된다[8,9].

2002년에 Kobayashi et al. [6]은 특발성 황반원공에서 발병 연령과 굴절력, 안축장의 변수에 따른 수술 결과에 대한 연구 를 진행하였다. 당시 연구에서는 나이가 적고 심한 근시가 있 는 경우 황반원공 발생이 유의하게 높아짐을 확인하였고 굴절 력은 황반원공의 크기나 수술 결과에는 영향을 미치치 않는 것 으로 발표하였다. 해당 연구의 주요 중점 결과는 다양한 변수 에 따른 수술 결과와의 관계로 안축장에 대한 결과는 저자들 의 연구와 단순 비교하기는 어려우나 당시 환자군을 안축장 길 이에 따라 나누어 비교하였는데, 본 연구 결과에서처럼 안축장 이 $23 \mathrm{~mm}$ 이하의 경우가 가장 많은 군으로 나타난 것을 확인 할 수 있었다.

이후 2005년 Shah et al. [8]은 35명의 3기 또는 4기 특발성 황 반원공 환자를 대상으로 대조군을 설정한 후 비교하였다. 황반 원공 환자들의 평균 안축장은 $22.94 \mathrm{~mm}$ 로 측정되었고 대조군 의 평균 안축장은 $23.48 \mathrm{~mm}$ 로 측정되어 황반원공 환자들이 대 조군에 비해 유의하게 짧은 안축장이 보임을 발표하여 저자들 의 결과와 일치하는 내용을 발표한 적이 있다.

또한 2011년에 발표한 Reibaldi et al. [7]은 단안 황반원공에 서 맥락막두께에 대한 연구를 발표하였으며, 이 대조군으로 환 자들의 fellow eye와 비교하였다. 당시 자료를 확인해 보면 황반 원공이 있는 쪽이 건강한 눈의 쪽에 비해 안축장이 짧게 측정
된 것으로 나타났다.

앞의 결과와는 반대되는 연구의 결과도 있었는데 2012년 Singh et al. [9]은 40명의 환자를 대상으로 안축장과 원발성 황 반원공의 관계에 대해서 환자 대조군 연구를 시행하였으며, 황 반원공군의 평균 안축장 길이는 $23.62 \mathrm{~mm}$, 대조군의 평균 안 축장은 $23.09 \mathrm{~mm}$ 로 측정되어 황반원공 환자들의 안축장 길이 가 대조군에 비해 유의하게 길게 나타났다고 발표하였다. 이외 에도 Iwase and Oveson [10]은 특발성 황반원공, 망막전막, 당뇨 망막병증, 망막정맥폐쇄 환자들의 안축장들을 비교한 적이 있 는데 당시 다른 질환에 비해 특발성 황반원공의 안축장이 유의 하게 길게 측정되었다고 발표한 바 있다.

황반원공의 최근 연구에서 중심와주위 및 시신경주변 망막 표면에서의 접선견인력이 황반원공 발생에 가장 큰 영향을 주 는 것으로 알려져 있으며[1-5] 또한 불완전한 후유리체 박리가 발생하면 망막표면의 접선견인력을 증가시킬 수 있다고 알려져 있다[12]. Shah et al. [8] 황반원공 환자에서 짧은 안축장이 작 은 유리체강 용적을 만들게 되고 이는 불완전한 후유리체 박 리에 영향을 미치게 되어 황반원공이 발생한다는 가설을 발표 하였다. 특발성 황반원공 환자의 사후 병리학적으로 분석한 연 구에서 눈의 마찰 및 변형이 작은 힘으로 만성적으로 가해지 는 경우 불완전하게 액화된 유리체 피질에 힘이 전달되고 이러 한 힘은 황반원공에서 가늘어진 중심와 근처의 후유리체피질 까지 전달되어 접선견인력을 강하게 만들어 황반원공을 일으킨 다고 하였다[13].

앞선 연구들을 인용하여 저자들의 연구 결과를 분석하면 짧 은 안축장은 유리체강내 작은 용적을 만들 수 있다. 이로 인 한 일상 생활에서 발생할 수 있는 눈꺼풀과 안구의 마찰 및 변 형에서 발생한 힘은 긴 안축장보다는 거리상 접선견인력이 발 생하는 망막표면에 더 빠르게 자주 도달할 수 있을 것으로 생 각된다. 이러한 현상이 작은 힘이지만 황반원공의 평균 발병나 이까지 오랜 시간 동안 지속된다면, 추가적인 연구가 더 필요 한 부분이지만 망막표면의 접선견인력에 영향을 주어 긴 안축 장에서 보다 황반원공 발생에 영향을 줄 수 있을 것으로 추측 해 볼 수 있다.

이전 Reibaldi et al. [7] 연구에서는 황반원공 환자의 양안 비 교에서 황반원공이 있는 눈이 반대안의 건강한 눈보다 짧은 안 축장을 가진다고 밝혔다. 저자들의 연구에서는 황반원공군에 서 병변측이 건강한 눈에 비해 짧은 안축장을 나타냈지만 유의 한 차이는 없었고 대조군에 비해 모두 안축장이 짧게 측정된 것으로 나타났다. 이는 일반적으로 안축장 길이는 양안이 비슷 하다고 알려져 있어 양안이 비슷한 결과가 나온 것으로 보이며 양안의 안축장 값이 적절하게 측정된 것을 확인할 수 있는 증 거로 생각된다. 또한 일측에 발생한 황반원공 환자를 대상으로 후향적으로 조사된 연구로, 건강한 눈을 추적 관찰하면 황반 원공이 발생할 가능성이 있어 추후 추가적인 추적 관찰이 필요 
할 것으로 보인다.

본 연구의 제한점으로는 100 명의 환자를 대상으로 한 연구 로 이전의 발표보다는 많은 분석을 시행하였지만 환자수가 제 한된 단점이 있다. 또한 백내장 수술을 하지 않은 환자를 대상 으로 연구를 진행하였으나 백내장 정도는 평가되지 않았고 백 내장 정도는 굴절력 및 전방 깊이에 영향을 줄 수 있어 각 군에 서 단순 비교하기는 어려울 것으로 보인다. 또한 이번 연구는 대 조군 비교 분석으로 황반원공 발생에 영향을 미칠 수 있는 다 른 요인이 함께 분석되지 않아 추후 추적 관찰 후에 추가적인 연구가 필요하다.

본 연구는 황반원공과 안축장과의 관계에 대한 환자 대조군 연구 중 가장 많은 수의 환자를 대상으로 조사하였으며 국내에 서는 처음으로 시행된 연구이며 또한 짧은 안축장이 황반원공 의 유발 요인으로 제시될 수 있는 추가적인 자료로서 의의가 있 을 것으로 생각된다.

\section{References}

1. Gass JD. Idiopathic senile macular hole. Its early stages and pathogenesis. Arch Ophthalmol 1988;106:629-39.

2. Gass JD. Reappraisal of biomicroscopic classification of stages of development of a macular hole. Am J Ophthalmol 1995;119:752-9.

3. Niwa $H$, Terasaki $H$, Ito Y, Miyake Y. Macular hole development in fellow eyes of patients with unilateral macular hole. Am J Ophthalmol 2005;140:370-5.

4. Tanner V, Chauhan DS, Jackson TL, Williamson TH. Optical coher- ence tomography of the vitreoretinal interface in macular hole formation. Br J Ophthalmol 2001;85:1092-7.

5. Fisher YL, Slakter JS, Yannuzzi LA, Guyer DR. A prospective natural history study and kinetic ultrasound evaluation of idiopathic macular holes. Ophthalmology 1994;101:5-11.

6. Kobayashi H, Kobayashi K, Okinami S. Macular hole and myopic refraction. Br J Ophthalmol 2002;86:1269-73.

7. Reibaldi M, Boscia F, Avitabile T, et al. Enhanced depth imaging optical coherence tomography of the choroid in idiopathic macular hole: a cross-sectional prospective study. Am J Ophthalmol 2011;151:112-7.e2.

8. Shah SP, Bunce C, Johnston RL, Laidlaw DA. Are biometric parameters a risk factor for idiopathic macular hole formation? Results of a matched case-control series. Br J Ophthalmol 2006;90:117-8.

9. Singh AJ, Muqit MM, Woon WH. Is axial length a risk factor for idiopathic macular hole formation? Int Ophthalmol 2012;32:393-6.

10. Iwase T, Oveson BC. Axial length in eyes with macular hole. Ophthalmology 2013;120:e67.

11. Gudmundsdottir E, Arnarsson A, Jonasson F. Five-year refractive changes in an adult population: Reykjavik Eye Study. Ophthalmology 2005;112:672-7.

12. Chauhan DS, Antcliff RJ, Rai PA, et al. Papillofoveal traction in macular hole formation: the role of optical coherence tomography. Arch Ophthalmol 2000;118:32-8.

13. Green WR. The macular hole: histopathologic studies. Arch Ophthalmol 2006;124:317-21. 


\section{국문초록}

\section{황반원공과 안축장과의 관계: 환자 - 대조군 연구}

목적: 황반원공 환자와 대조군에서 안축장을 비교하고 그 차이를 알고자 하였다.

대상과 방법: 한 눈에 특발성 전층황반원공으로 진단받은 100 명을 대상으로 원공이 발생한 100 안과 원공이 발생하지 않은 반대쪽 100 안, 동일 연령대의 백내장수술을 시행한 대조군 100명 100안을 대상으로 안축장을 비교 분석하였다.

결과: 황반원공이 발생한 눈에서 안축장 길이는 평균 $22.71 \pm 0.92 \mathrm{~mm}$ 였고, 반대쪽의 건강한 눈은 $22.81 \pm 0.89 \mathrm{~mm}$ 로 유의한 차이가 없었다 $(p=0.477)$. 대조군에서 안축장 길이는 $23.37 \pm 0.68 \mathrm{~mm}$ 로 측정되었다. 황반원공안과 대조군을 비교했을 때와 황 반원공 환자의 반대쪽 건강한 눈과 대조군을 비교했을 때 통계적으로 유의한 차이를 보였다 $(p<0.001)$.

결론: 특발성 황반원공에서 대조군에 비하여 유의하게 짧은 안축장 길이가 확인되었고 이는 황반원공의 유발 요인으로 고려 가능할 것 으로 생각된다. 